\title{
AVALIAÇÃO DE MÉTODOS DE REDUÇÃO DE SONDAGENS BATIMÉTRICAS AO NÍVEL D'ÁGUA INSTANTÂNEO PARA MONITORAMENTO DE ASSOREAMENTO: ESTUDO DE CASO DO RESERVATÓRIO DA USINA HIDRELÉTRICA MAUÁ
}

\author{
Evaluation methods of reducing bathymetric surveys to the water level \\ instantaneous water for monitoring siltation: case study of the hydroelectric power \\ plant reservoir Mauá
}

\author{
Wesley Andersen Mezine ${ }^{1}$ \\ Marcos Alberto Soares ${ }^{1}$ \\ Pedro Luis Faggion² \\ Luís Augusto Koenig Veiga² \\ Carlos Aurelio Nadal ${ }^{2}$ \\ ${ }^{1}$ Copel Geração e Transmissão S.A. - Curitiba - Paraná - Brasil \\ E-mail:wesley.mezine@copel.com; marcos.asoares@copel.com; \\ 2Universidade Federal do Paraná UFPR - Curitiba - Paraná - Brasil \\ E-mail: pedro.faggion@ufpr.br, kngveiga@ufpr.br, cnadal@ufpr.br
}

\section{Resumo:}

O setor elétrico brasileiro está estruturado para garantir o fornecimento de energia elétrica à toda a nação, sendo que a geração é feita em sua maioria através de usinas hidrelétricas, onde o reservatório desempenha peça fundamental no processo de geração. $O$ assoreamento de reservatórios pode impactar diretamente na operação e manutenção de usinas hidrelétricas, reduzindo a sua capacidade de armazenamento e vida útil. O monitoramento e a avaliação do volume assoreado do reservatório é uma importante ferramenta para o acompanhamento do processo de assoreamento e para fornecer as informações necessárias para embasar a tomada de decisões de forma a evitar a interrupção no processo de geração de energia, bem como danos ambientais. Neste trabalho foram testados três formas diferentes de realizar a redução do nível d'água instantâneo em levantamentos realizados com um ecobatímetro voltadas para o monitoramento de reservatórios: observações com RTK móvel, medições feitas na margem do reservatório com o RTK estático e leituras da régua linimétrica. Através do cálculo das incertezas verticais totais e teste estatístico das duas médias constatou-se que as duas ultimas técnicas apresentaram resultados equivalentes e sua aplicação é viável na área de estudo.

Palavras-chave: Assoreamento de reservatórios, levantamento batimétrico, redução de sondagens batimétricas e incertezas verticais totais. 


\begin{abstract}
:
The Brazilian power industry is structured to ensure the supply of electricity to the entire nation, since the generation is done mostly through hydroelectric plants where the reservoir plays a key part in the generation process. The silting of reservoirs can directly impact in the operation and maintenance of hydroelectric plants, reducing the capacity storage and useful life. The monitoring and evaluation of the reservoir silted volume it's an important tool for follow the process and too provide the necessary information to support decision form to avoid interruption in the power generation process, as well as environmental damage. In this work it were tested three different ways to carry out the reduction in the instant water level in surveys conducted with a echo sounder for reservoirs monitoring: using the RTK observations done during the reservoir surveying, the measurements made on the right bank of the reservoir with the RTK fixed in one point, and readings in a limnimetric scale (water level gauging station).Through calculations of total vertical uncertainty and statistical test of the two averages, it was observed that the latter two techniques showed similar results and its application is feasible in study area.
\end{abstract}

Keywords: Reservoirs siltation, bathymetric survey, reduction of bathymetric surveys and total vertical uncertainties.

\title{
1. Introdução
}

Monitorar o assoreamento de reservatórios artificias destinados a geração de energia elétrica é importante, pois os depósitos de sedimentos reduzem a capacidade de armazenamento de água, afetando a operação e manutenção da Usina. Uma situação alarmante, refere-se ao estudo de caso do reservatório de Tucuruí, que em uma hipótese mais pessimista, desconsiderando os reservatórios de montante, a soleira da tomada d'água poderia ser alcançada pelo depósito de sedimentos em 78 anos (Carvalho et al.,2003). A Usina de Itiquira (Mato Grosso) poderá ter o volume total do reservatório assoreado, no nível d'água máximo normal, em 14 anos (Carvalho et al., 2000).

O volume assoreado dos reservatórios é determinado utilizando dados cartográficos oriundos de diferentes épocas, métodos, técnicas e sistemas geodésicos de referência (SGR). Comparar dados levantados em diferentes épocas com diferentes técnicas é relativamente complexo, em algumas situações as diferenças encontradas entre os produtos utilizados nas análises não representam o assoreamento. As discrepâncias apresentadas por diferentes metodologias e tecnologias afetam diretamente na análise dos resultados.

Este trabalho propõe avaliar a qualidade de três métodos de redução das sondagens batimétricas ao nível instantâneo d'água utilizando-se observações feitas com posicionamento por satélite através da técnica Real Time Kinematic (RTK) e também da régua linimétrica instalada na barragem. A partir das medições com RTK foram aplicados dois métodos de redução são estes: Nível d'água RTK Móvel (nível d'água medido com o receptor/ antena rover instalado no barco) e Nível d'água RTK Estático (nível d'água mensurado com RTK na margem do reservatório).

Foram realizadas linhas de sondagens batimétricas regulares, transversais a margem do reservatório, e linhas de verificações perpendiculares as linhas regulares e longitudinais ao curso d'água. Com estes dados determinou-se os valores do erro total propagado (ETP) e foram comparados os resultados obtidos por cada técnica de redução aos valores de tolerância para a Incertezas Verticais Total (IVT). Por fim aplicou-se o teste de hipóteses das duas médias para verificar se os resultados obtidos nas análises. 


\section{Revisão de Literatura}

\subsection{Assoreamento de reservatórios}

A sedimentação compreende a erosão; o deslocamento de partículas até o curso d'água, pelo vento, enxurradas e outros; o transporte de sedimentos; o depósito no leito do rio, lagos naturais e artificiais; e a compactação. A sedimentação refere-se ao assoreamento de reservatórios, utilizados para fins de geração de energia elétrica. O assoreamento é um depósito de sedimentos permanente ou quase permanente (Carvalho, 2008). Ele ocorre devido a formação de um lago calmo lugar de um curso d'água que fluía rapidamente, a morfologia do rio é alterada provocando a sedimentação e deposição no leito, ocupando espaço no lago e diminuindo a capacidade do reservatório (Bronsvoort, 2013).

A medição do assoreamento do reservatório identifica se o depósito de sedimentos não reduzirá a sua vida útil (econômica). Esta ocorre quando os depósitos de sedimentos alcançam a soleira da tomada d'água impossibilitando a operação adequada do empreendimento (Carvalho, 2008).

Os sedimentos são transportados em suspensão, rolando ou deslizando sobre a camada de fundo e intercalando por suspensão e acumulo no fundo (Twenhofel, 1939). Inicialmente as partículas com maior diâmetro, seixos e areia grossa são depositados no leito do canal. Na sequência ocorre o depósito da areia fina e do silte grosso. Partículas menores com silte fino e argila percorrem o lago em suspensão. $\mathrm{O}$ barramento age como um obstáculo, impedindo que uma grande quantidade de sedimentos passe para jusante (Da Silva, 2007).

\subsection{Levantamento Batimétrico}

O levantamento batimétrico é a atividade principal de um levantamento hidrográfico e tem como objetivo determinar a profundidade do fundo submarino, rios, córregos, lagos artificiais e naturais, atrelando a sua respectiva posição espacial. $\mathrm{Na}$ coleta de dados são utilizados geralmente ecobatímetros, sonares de varredura lateral, perfilamento a Laser, imagens de satélites e outros.

Os levantamentos batimétricos são executados também com a finalidade de obter o volume de reservatórios de águas artificiais. Através de séries temporais de dados é possível obter o volume assoreado, a partir da comparação de Modelos Digitais do Terreno (MDT). Esta comparação pode ser feita utilizando dados levantados inicialmente, antes do enchimento do reservatório, e um levantamento batimétrico realizado após a formação do lago, ou comparando duas campanhas batimétricas realizadas em momentos distintos após o enchimento do lago. A coleta de dados envolve as seguintes etapas: planejamento do recobrimento batimétrico, levantamento de campo, processamento dos dados e elaboração de mapas digitais, geração de curvas cota área e cota volume, e MDT (Kuwajima, 2012).

A frequência que devem ser realizados os levantamentos batimétricos é apresentada na Tabela 1, a classificação não é rígida, pode ter diferentes conceitos em outros países. 
Tabela 1: Frequência desejável para levantamentos batimétricos de reservatórios

\begin{tabular}{l|c|c}
\hline $\begin{array}{c}\text { Porte do } \\
\text { Reservatório }\end{array}$ & Volume $\left(\mathbf{1 0}^{\mathbf{6}} \mathbf{~ m}^{\mathbf{3}}\right)$ & $\begin{array}{c}\text { Intervalo entre } \\
\text { levantamentos }\end{array}$ \\
\hline Pequeno & $<10$ & 2 anos \\
\hline Médio & 10 a 100 & 5 anos \\
\hline Grande & $>100$ & 10 anos \\
\hline
\end{tabular}

* FONTE: adaptada de Carvalho et al. (2000)

Para realizar medidas de profundidades o principal instrumento utilizado é o ecobatímetro. Este pode ser de feixe único (um transdutor) e multifeixe (um projetor e um hidrofone). A largura do feixe depende do tamanho do transdutor e do comprimento da onda acústica. Maior frequência ou maior transdutor está relacionada a menor feixe. Feixes mais estreitos $2^{\circ}$ (graus) a $5^{\circ}$ (graus) são aplicados quando se deseja alta precisão (OHI, 2005).

Segundo Ribeiro; Centeno; Krueger (2008) e Tedesco (2003), as observações realizadas por um ecobatímetro consistem em emitir um feixe de ondas sonoras ou ultrassonoras, orientadas verticalmente ao transdutor (emissor), percorrendo o meio líquido até atingir o fundo submarino, do rio ou do lago, este é refletido e retorna a superfície sendo detectado pelo transdutor (receptor). O percurso de ida e volta do sinal é transformado em profundidade pela equação:

$$
p=\frac{1}{2} v \cdot t
$$

Onde:

$p$ : profundidade;

v: velocidade de propagação do som na água;

$t$ : tempo de ida e volta do sinal, do transmissor para o fundo e deste para o receptor.

\subsection{Real Time Kinematic (RTK)}

O posicionamento das sondagens realizadas com um ecobatímetro, podem ser determinadas através de um sistema RTK. Este basicamente contém dois conjuntos receptores/antenas GNSS L1 ou L1 e L2, um link de comunicação de rádio para transmitir (a uma taxa mínima de 2400 bits por segundo) e receber as correções das observáveis da estação base e um software para realizar o processamento dos dados em tempo real. No sistema de rádio utiliza as faixas de frequência Ultra High Frequency (UHF) ou Very High Frequency (VHF) (Monico, 2008).

As correções diferenciais geradas da estação base, são aplicadas diretamente na fase observada da estação itinerante e são transmitidas em tempo real através de um protocolo de comunicação. A solução fixa das ambiguidades da fase da onda portadora dos receptores em movimento utiliza a inicialização automática "On the fly" (OTF) ou "On the way" (OTW). O tempo de fixação das ambiguidades (TTFA) depende do comprimento da linha de base e poderá ser igual a uma época para determinadas situações. (OHI, 2005; Ramos, 2007; Seeber, 2003). Em linhas bases curtas é 
possível eliminar os erros dos: relógios, efeitos atmosféricos e orbitas dos satélites, que são eliminados através da correlação das observações das estações (Ramos, 2007).

\subsection{Integração ecobatímetro, GNSS e sistema Inercial}

A integração envolve três sistemas: o acústico, o inercial e o GNSS. Ela é realizada em um computador portátil, através de um software específico. A posição de cada sensor utilizado é determinada em relação ao sistema de referência da embarcação (centro de massa ou arbitrário).

Trabalhos realizados em águas interiores, no qual a finalidade não é navegação, geralmente não são utilizados Inertial Measurement Unit (IMU), somente receptores GNSS e ecobatímetro. A integração dos dados de profundidade e posição neste caso é feita com a instalação do receptor GNSS e do sondador acústico em uma mesma linha vertical.

\subsection{Reduções Batimétricas}

As reduções batimétricas são obtidas através das correções dos seguintes erros: instrumental, da posição do transdutor, dos movimentos da embarcação e das condições ambientais. A correção instrumental consiste em fazer coincidir o instante do tempo de transmissão do sinal acústico com o valor zero da escala de medição de profundidade. A correção da posição transdutor é positiva e corresponde a distância deste ao nível instantâneo da água. As correções dos movimentos da embarcação têm como objetivo eliminar os desvios do feixe acústico, devido as oscilações do barco no deslocamento sobre as linhas de sondagem, para tal são utilizados sensores que medem as rotações e translações do sistema de coordenadas da embarcação. As correções das condições ambientais são: da maré e das variações na velocidade de propagação do som na água (Ramos, 2007).

A profundidade reduzida é obtida pela equação(Ramos, 2007):

$$
p_{r}=\frac{1}{2} v \cdot t+k+D_{m}+\varepsilon
$$

Onde:

$p_{r}$ : profundidade reduzida (em relação a um nível de redução);

$v$ : velocidade média de propagação do som na água;

$t$ : intervalo de tempo entre a emissão e recepção do feixe acústico no transdutor;

$k$ : índice de correção instrumental do ecobatímetro;

$D_{m}$ : profundidade de imersão do transdutor em relação ao nível d'água instantâneo;

$\varepsilon$ : outras correções: variações dinâmicas de calado, variação do nível d'água, controle do nível d'água e outros. 
Neste trabalho não é necessário corrigir os efeitos de maré, pois o mesmo foi realizado em um reservatório.

\subsection{Incerteza Vertical Total (IVT)}

A IVT agrega todas as incertezas presentes nas medidas das profundidades reduzidas. A incerteza refere-se ao nível de confiança de $95 \%$, na correção dos erros sistemáticos. Conhecidos os erros a IVT pode ser calculada pela equação (OHI, 2008):

$$
I V T= \pm \sqrt{a^{2}+(b . d)^{2}}
$$

Onde:

$a$ : parcela da incerteza que não depende da profundidade;

$b$ : coeficiente que representa a parte da incerteza que depende da profundidade;

$d$ : profundidade.

Os parâmetros para o cálculo do IVT, conforme as ordens do levantamento são (OHI,2008):

- Ordem Especial: $\mathrm{a}=0,025 \mathrm{~m}$ e $\mathrm{b}=0,0075$;

- Ordem 1a: $\mathrm{a}=0,5 \mathrm{~m} \mathrm{e} \mathrm{b}=0,013$;

- Ordem 1b: $\mathrm{a}=0,5 \mathrm{~m} \mathrm{e} \mathrm{b}=0,013$;

- Ordem 2: $\mathrm{a}=1,0 \mathrm{~m} \mathrm{e} \mathrm{b}=0,023$.

O cálculo do Erro Total propagado (ETP), ao nível de confiança de $95 \%$ é obtido pela equação (USACE, 2004, apud Ramos, 2007):

$$
E T P=1,96 \cdot \sqrt{\sigma_{B I A S}^{2}+\sigma_{E R R O}^{2}}
$$

Onde:

$\sigma_{B I A S}$ :média das diferenças entre as intersecções das sondagens regulares e de verificação;

$\sigma_{E R R O}$ : desvio padrão das diferenças entre as intersecções das sondagens regulares e de verificação.

O ETP tem que ser inferior a IVT calculado para cada tipo de levantamento, conforme as especificações da OHI para levantamentos hidrográficos S-44 (Ramos, 2007). 


\section{Metodologia}

\subsection{Localização Usina Hidrelétrica Mauá}

A usina hidrelétrica Mauá esta localizada entre as coordenadas geodésicas $24^{\circ} 03^{\prime} 32^{\prime}$ ' S e $50^{\circ} 42^{\prime} 44^{\prime \prime}$ W, e $24^{\circ} 03$ '36" S e 5042'18” W (Sistema Geodésico de Referência SIRGAS 2000) no rio Tibagi, município de Telêmaco Borba no estado do Paraná. A potência instalada é de 352 MW na usina principal e $11 \mathrm{MW}$ na usina secundária, o que corresponde a uma potência total de 363 MW. O reservatório tem uma área de $83,9 \mathrm{~km}^{2}$ quando operado no nível máximo normal com altitude ortométrica de 635 m (UHE Mauá, 2014).

\subsection{Execução Levantamento Batimétrico}

A Diretoria de Hidrografia e Navegação orienta que o espaçamento entre as linhas de sondagens batimétricas regulares (transversais a margem do reservatório), devem ter equidistância de $1 \mathrm{~cm}$ na escala do mapa gerado como produto da batimetria executada (Carvalho et al., 2000). Considerando que os mapas batimétricos serão elaborados na escala 1: 1000, as linhas de sondagem batimétricas foram realizadas a cada $10 \mathrm{~m}$, o que representa $1 \mathrm{~cm}$ na escala 1: 1000 .

Para execução dos levantamentos batimétricos foram utilizados os seguintes equipamentos:

- Receptor GNSS TOPCON HIPER LITE L1 e L2 (Topcon, 2004):

○ Tempo de inicialização de $5 \mathrm{~s}$ até 10 min, depende do comprimento da linha de base e dos efeitos de multicaminho;

○ Ambiguidade inicializada: OTF (L1 ou L1 e L2);

○ Latência 20 a 30ms, para extrapolação;

- Saída NMEA 0183 versões 2.1, 2.2, 2.3 e 3.0;

○ Precisão Horizontal no modo cinemático em tempo real (RTK), de $10 \mathrm{~mm}$ + 1 ppm x comprimento da linha de base;

○ Precisão Vertical modo cinemático em tempo real (RTK), de $15 \mathrm{~mm}+1$ ppm x comprimento da linha de base;

- Frequência do Link de Rádio, de 902 a 928 MHz.

- Ecobatímetro Reson Navisound 215 (Teledyne, 2014):

○ Frequência Padrão: 28 - 35 e 190-225 kHz;

○ Potência Máxima: $300 \mathrm{~W}$; 
○ Acurácia: $1 \mathrm{~cm}$ para $210 \mathrm{kHz}(1 \sigma)$ e $7 \mathrm{~cm}$ para $33 \mathrm{kHz}(1 \sigma)$;

- Canais: $1 / 2$;

○ Alcance da Profundidade 0,2 a 600m.

O levantamento foi executado numa área de 170382,44 $\mathrm{m}^{2}$, situada imediatamente a montante do barramento com extensão de $300 \mathrm{~m}$. Foram levantadas 31 linhas de sondagens batimétricas regulares e 10 linhas de verificação com espaçamento de $50 \mathrm{~m}$ (9 linhas) e $100 \mathrm{~m}$ (1 linha) entre elas. O espaçamento máximo definido pela Organização Hidrográfica Internacional correspondente a 15 vezes o espaçamento das sondagens batimétricas regulares $(10 \mathrm{~m})$ e eiva a 150 m neste caso (OHI, 2008). As linhas de sondagens realizadas são apresentadas na Figura 1.

A distância entre a estação base e a estação móvel instalada no barco é menor do que $1000 \mathrm{~m}$ para todas as sondagens batimétricas realizadas. A taxa de registro das observações GNSS é de 1 segundo.

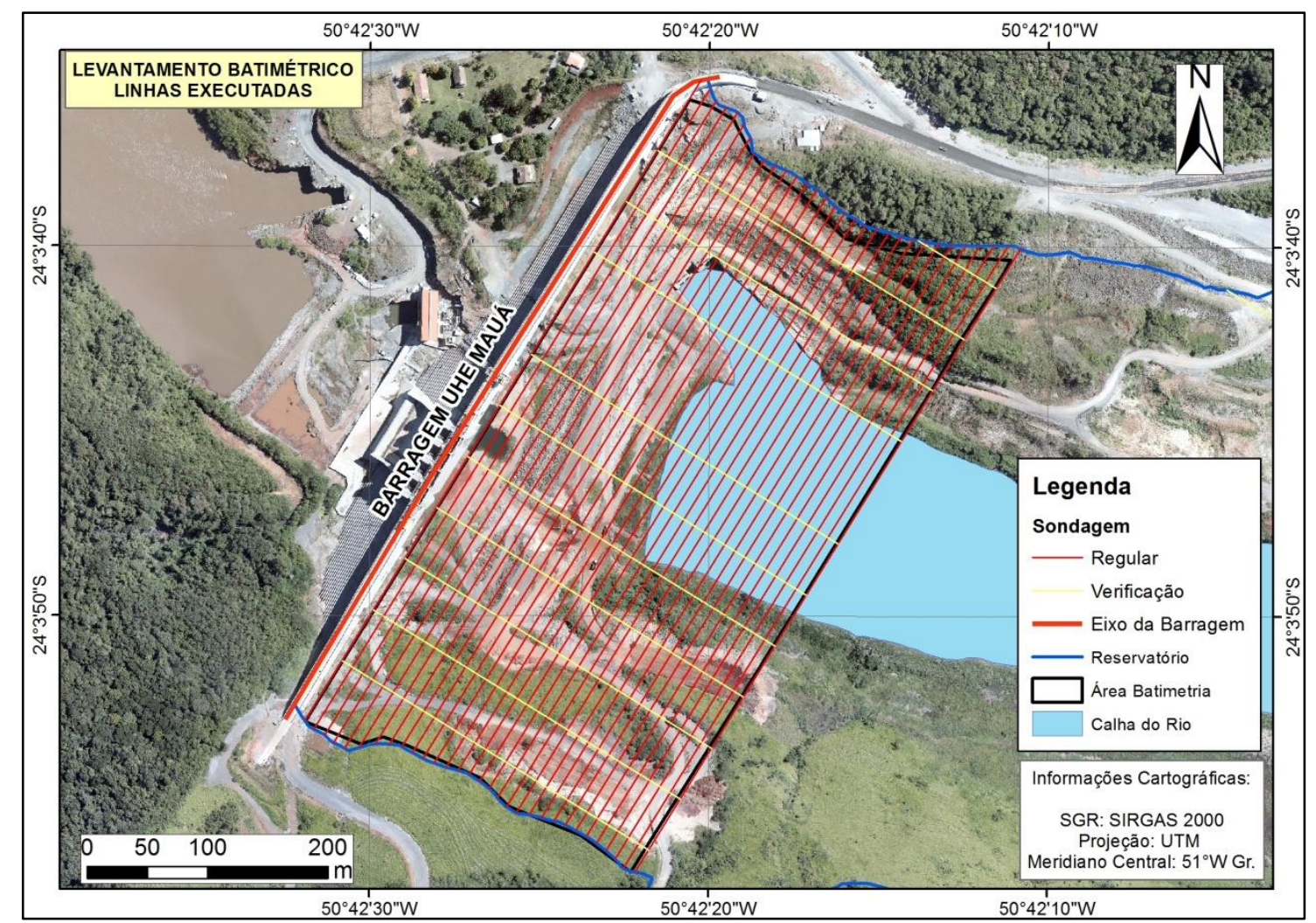

Figura 1: Sondagens Batimétricas

A antena GNSS e o transdutor foram instalados na mesma linha de referência vertical (com relação ao espelho d'água), fixados em uma mesma haste metálica, que coincide com o eixo $\mathrm{Z}$ do sistema de coordenadas da embarcação. Na Figura 2 apresenta-se os equipamentos instalados no barco. A instalação da antena GNSS e do transdutor do ecobatímetro de forma sincronizada permite a eliminação das medidas dos offsets e das rotações em torno do eixo $\mathrm{Z}$ (heading) Considerando ainda a velocidade da embarcação, a abertura do feixe cônico e o fato de o reservatório não ter correnteza e ondas não foi necessário corrigir pitch, roll e heave (Ferreira, 
2013). Então antes do início da coleta de dados foram determinados os seguintes offsets verticais:

- Altura vertical da antena GNSS em relação ao nível instantâneo da água;

- Imersão do transdutor em relação ao nível da água instantâneo.

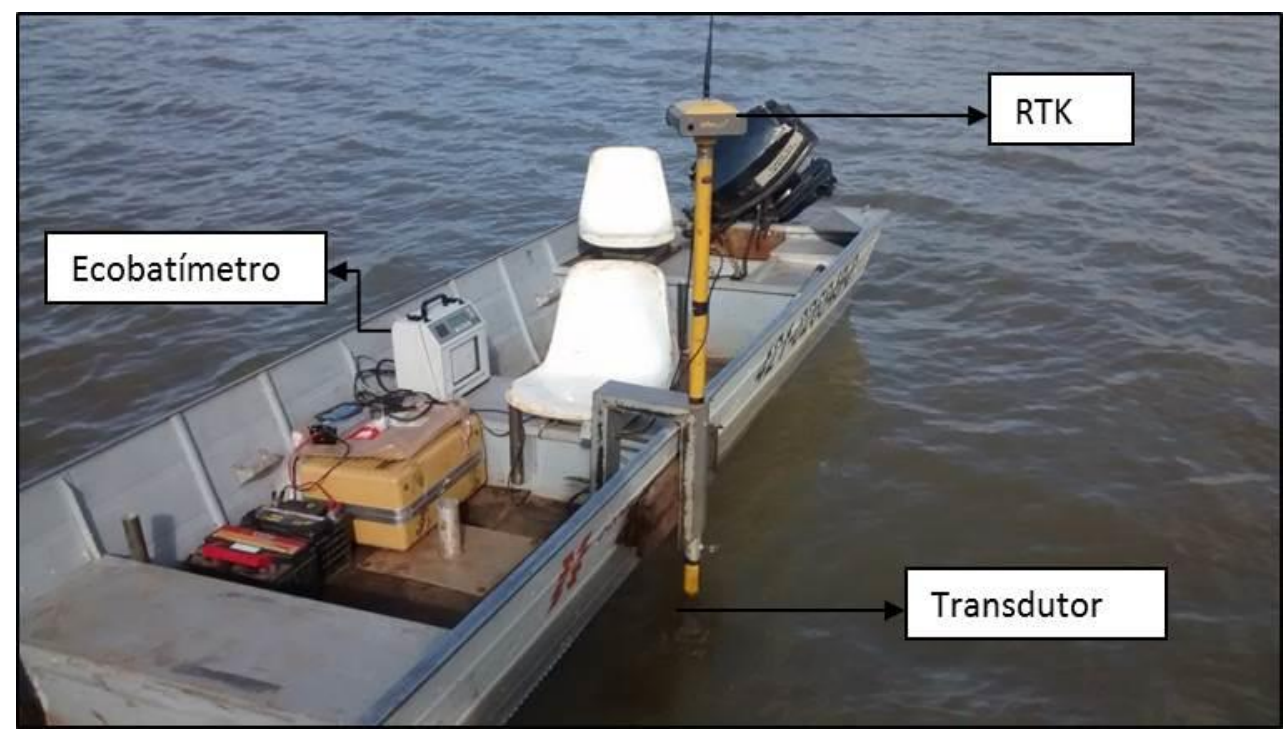

Figura 2: Embarcação e equipamentos utilizados no levantamento batimétrico

\subsection{Processamento dos dados}

A integração dos dados batimétricos e de posição planimétrica realizaram-se através da sincronização do tempo, vinculado ao tempo GNSS. A latência entre a observação dos dados GNSS e a transmissão das correções da fase da portadora, da estação base para estação móvel, foi 1 segundo. O pré-processamento dos dados foi realizado no software Hypack 2010. No processamento foram aplicadas as correções dos offsets verticais, latência e eliminação dos erros grosseiros (spikes) oriundos do posicionamento e da batimetria.

Considerando que a execução do levantamento batimétrico é realizada utilizando o nível d'água instantâneo do reservatório como nível de redução das sondagens batimétricas, é necessário corrigir as oscilações do nível d'água em função do tempo com intuito de obter as profundidades reais. Estas correções podem ser feitas: aplicando as altitudes observadas (corrigidas) em tempo real obtidas com RTK, rastreio GNSS do nível d'água antes e após a coleta de dados batimétricos e correção das profundidades utilizando as observações do nível d'água a partir de réguas linimétricas. Na UHE Mauá existe uma estação telemétrica que observa de modo automático o nível d'água do reservatório em intervalos de 15 em $15 \mathrm{~min}$.

Foram adotadas as seguintes técnicas para redução das sondagens batimétricas:

1. As profundidades reduzidas foram determinadas considerando o valor da altitude elipsóidica do nível d'água obtida em tempo real durante a coleta de dados (RTK instalado no barco); 
2. As profundidades reduzidas foram obtidas considerando as observações do nível d'água realizados na margem do reservatório no início e final do levantamento batimétrico com RTK (Figura 5).

3. As profundidades reduzidas foram obtidas aplicando as diferenças de níveis observadas pela estação telemétrica a cada $15 \mathrm{~min}$.

Na técnica 1 utilizou-se a Equação 5, na técnica 2 a Equação 6 e na técnica 3 a Equação 7 para obter as altitudes elipsóidicas da nuvem de pontos do fundo do reservatório:

$$
\begin{gathered}
h_{\text {fundo }}=h_{N A R T K}-l_{m}-\left(p_{\text {obs }}+D_{m}\right) \\
h_{\text {fundo }}=h_{N A-d i}-\left(p_{\text {obs }}+D_{m}\right) \\
h_{\text {fundo }}=h_{N A \text { régua }}-\left(p_{\text {obs }}+D_{m}\right)
\end{gathered}
$$

Onde:

$h_{\text {fundo }}$ : altitude elipsóidica do fundo do reservatório;

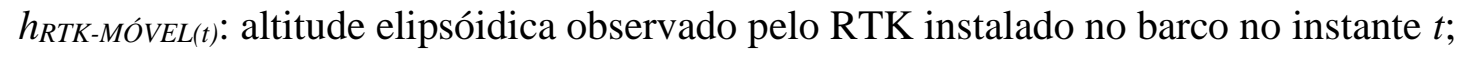

$h_{N A-d i}$ : altitude elipsóidica do nível d'água estimado, para o instante $t$;

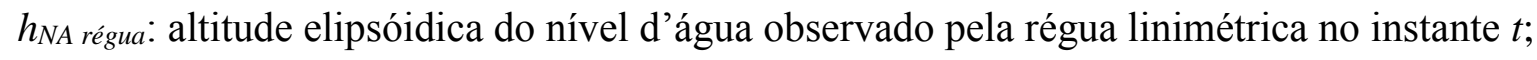

pobs: profundidade observada pelo ecobatímetro;

$l_{m}$ : altura vertical da antena GNSS em relação ao nível d'água instantâneo;

$D_{m}$ : profundidade de imersão do transdutor em relação ao nível d'água instantâneo.

\section{Resultados}

\subsection{Análise das Incertezas Verticais Totais (IVT)}

Com o intuito de verificar a qualidade posicional e vertical das profundidades medidas, realizouse uma coleta de dados complementar, executada em sentido transversal as linhas de sondagens regulares (perpendicular ao talvegue) e denominadas sondagens de verificações (longitudinais ao curso d'água) com intuito de obter redundância de observações. Nesta etapa comparou-se os valores das altitudes obtidos entre as linhas de sondagens regulares e de verificação com objetivo de estimar a precisão do levantamento batimétrico. Como não é possível reocupar os pontos observados, em função das condições de coleta de dados, adota-se um raio de busca para 
identificar pontos dentro de uma área que deveriam ter valores de profundidades iguais ou com diferenças entre eles não superior a uma tolerância estabelecida a priori. Neste trabalho adotouse um raio de busca de $50 \mathrm{~cm}$, considerando o PEC planimétrico classe "A" para mapas na escala 1: 1000 , que corresponde a $0,5 \mathrm{~mm}$ na escala do mapa.

Realizado o processamento dos dados determinaram-se os valores do ETP para os três métodos adotados na redução das sondagens batimétricas. Nas tabelas 3 a 5 apresentam-se os resultados.

Tabela 2: Avaliação da IVT- Nível de redução das sondagens batimétricas obtidos a partir do nível d'água RTK móvel

\begin{tabular}{|c|c|c|c|c|}
\hline \multicolumn{2}{|c|}{ Sondagens Batimétricas } & \multirow{2}{*}{\begin{tabular}{|l|} 
Média (m) \\
Desvio \\
Padrão (m)
\end{tabular}} & \multirow{2}{*}{$\begin{array}{l}0,07 \\
0,39\end{array}$} & \multirow[b]{3}{*}{$\begin{array}{l}\text { Atende } \\
\text { em (\%): }\end{array}$} \\
\hline Intersecções & 905 & & & \\
\hline \multirow[t]{3}{*}{$\begin{array}{l}\text { Profundidade } \\
\text { Média }(\mathrm{m})\end{array}$} & 41,45 & $\operatorname{ETP}(\mathrm{m})$ & 0,77 & \\
\hline & \multirow{2}{*}{$\begin{array}{l}\text { Tolerância } \\
\text { IHO }\end{array}$} & $\begin{array}{l}\text { IVT Ordem } \\
\text { 1a }(\mathrm{m})\end{array}$ & 0,74 & 96,24 \\
\hline & & $\begin{array}{l}\text { IVT Ordem } \\
\text { Especial } \\
(\mathrm{m})\end{array}$ & 0,40 & 71,93 \\
\hline
\end{tabular}

Na tabela 2 observa-se que o processamento dos dados batimétricos, considerando que as altitudes elipsoidais do nível d'água instantâneo foram obtidas a partir do posicionamento RTK instalado na embarcação (durante a execução da batimetria). Analisando a tabela observa-se que o ETP do levantamento é superior ao IVT das ordens especial e 1a, porém mais de 95\% (nível de confiança) das intersecções apresentam diferenças menores que o IVT máximo para a ordem 1a.

Tabela 3: Avaliação da IVT - Nível de redução das sondagens batimétricas obtidos a partir do nível d'água RTK estático

\begin{tabular}{|c|c|c|c|c|}
\hline $\begin{array}{c}\text { Sondagens } \\
\text { Batimétricas }\end{array}$ & & Média (m) & 0,01 & \\
\hline Intersecções & 905 & $\begin{array}{l}\text { Desvio } \\
\text { Padrão (m) }\end{array}$ & 0,31 & \multirow[b]{2}{*}{$\begin{array}{l}\text { Atende } \\
\text { em (\%) }\end{array}$} \\
\hline $\begin{array}{l}\text { Profundidade } \\
\text { Média (m) }\end{array}$ & 41,45 & ETP (m) & 0,61 & \\
\hline & \multirow[t]{2}{*}{$\begin{array}{l}\text { Tolerância } \\
\text { IHO }\end{array}$} & $\begin{array}{l}\text { IVT Ordem } \\
1 \mathrm{a}(\mathrm{m})\end{array}$ & 0,74 & 98,78 \\
\hline & & $\begin{array}{l}\text { IVT Ordem } \\
\text { Especial } \\
\text { (m) }\end{array}$ & 0,40 & 77,02 \\
\hline
\end{tabular}

Na tabela 3 observa-se que o ETP do levantamento é menor que a IVT da Ordem 1a. O ETP do levantamento é menor que os apresentados pelos métodos de redução das sondagens batimétricas utilizando o Nível d'água RTK móvel, realizando observações a partir da embarcação. 
Tabela 4: Avaliação da IVT - Nível de redução das sondagens batimétricas obtidos a partir do nível d'água da régua linimétrica

\begin{tabular}{|c|c|c|c|c|}
\hline \multicolumn{2}{|c|}{ Sondagens Batimétricas } & Média (m) & 0,02 & \multirow[b]{3}{*}{$\begin{array}{l}\text { Atende } \\
\text { em (\%): }\end{array}$} \\
\hline Intersecções & 905 & $\begin{array}{l}\text { Desvio } \\
\text { Padrão (m) }\end{array}$ & 0,31 & \\
\hline $\begin{array}{l}\text { Profundidade } \\
\text { Média }(\mathrm{m})\end{array}$ & 41,45 & $\mathrm{ETP}(\mathrm{m})$ & 0,62 & \\
\hline \multirow{2}{*}{\multicolumn{2}{|c|}{$\begin{array}{l}\text { Tolerância } \\
\text { IHO }\end{array}$}} & $\begin{array}{l}\text { IVT Ordem } \\
1 \mathrm{a}(\mathrm{m})\end{array}$ & 0,74 & 98,56 \\
\hline & & \begin{tabular}{|l|} 
IVT Ordem \\
Especial \\
$(\mathrm{m})$ \\
\end{tabular} & 0,40 & 77,24 \\
\hline
\end{tabular}

Na tabela 4 observa-se que o ETP do levantamento é menor que a IVT da Ordem 1a.

\subsection{Teste de Hipóteses da diferença entre duas médias populacionais}

Com os valores das médias e desvios padrões populacionais conhecidos (Tabelas 3 a 5), aplicouse o teste de hipóteses (Equações 8 e 9):

$$
\begin{aligned}
& H_{0}: \mu_{1}-\mu_{2}=0 \\
& H_{1}: \mu_{1}-\mu_{2} \neq 0
\end{aligned}
$$

Onde:

$H_{0}$ : hipótese nula;

$H_{1}$ : hipótese alternativa;

$\mu_{1}$ : média populacional da amostra 1 ;

$\mu_{2}$ : média populacional da amostra 2 .

Para o teste de hipóteses adotou-se um nível de significância de 5\%. Como são conhecidos os desvios padrões populacionais utilizou-se a distribuição normal padronizada. $\mathrm{O} z_{\mathrm{c}}$ é calculado pela Equação 10 (Marques, J. M., Marques, M. A. M., 2005):

$$
z_{c}=\frac{\bar{x}_{1}-\bar{x}_{2}}{\sqrt{\frac{\sigma_{1}^{2}}{n_{1}}+\frac{\sigma_{2}^{2}}{n_{2}}}}
$$

Onde: 
$\bar{x}_{1}$ : média populacional da amostra 1 ;

$\bar{x}_{2}$ : média populacional da amostra 2 ;

$\sigma_{1}^{2}$ : variância populacional da amostra 1 ;

$\sigma_{2}^{2}$ : variância populacional da amostra 2 ;

$n_{1}:$ amostra 1 ;

$n_{2}: \operatorname{amostra} 2$.

Apresenta-se na Tabela 5 os resultados do teste de hipótese.

Tabela 5: Teste de hipóteses para duas médias populacionais

\begin{tabular}{|c|c|c|c|c|}
\hline Redução & $\mu(\mathrm{m})$ & $\sigma(\mathbf{m})$ & $\mathbf{n}$ & \\
\hline Nível d'água Régua & 0,02 & 0,31 & \multirow{3}{*}{905} & \\
\hline Nível d'água RTK Móvel & 0,07 & 0,39 & & \\
\hline Média Nível d'água RTK Estático & 0,01 & 0,31 & & \\
\hline Teste & $\bar{x}_{1}-\bar{x}_{2}$ & $\sqrt{\frac{\sigma_{1}^{2}}{n_{1}}+\frac{\sigma_{2}^{2}}{n_{2}}}$ & $z_{c}$ & Resultado \\
\hline Nível d'água RÉGUA - Nível d'água RTK Móvel & $-0,05$ & 0,02 & $-3,16$ & Rejeita-se $H_{0}$ \\
\hline Nível d'água Régua - Nível d'água RTK Estático & 0,01 & 0,01 & 0,84 & Não rejeita-se $H_{0}$ \\
\hline Nível d'água RTK Móvel - Nível d'água RTK Estático & 0,06 & 0,02 & 3,91 & Rejeita-se $H_{0}$ \\
\hline
\end{tabular}

Na Tabela 5 observa-se que para um nível de confiança de $95 \%$ as médias, das IVT dos métodos de redução ao nível' água instantâneo com RTK Estático e régua linimétrica, são equivalentes.

\section{Conclusões}

A redução de sondagens batimétricas ao nível d' água instantâneo com observações realizadas com o barco em movimento, RTK móvel, não atendeu a tolerância definida pela OHI para levantamentos hidrográficos em profundidades entre $40 \mathrm{~m}$ e $100 \mathrm{~m}$, ordem $1 \mathrm{a}$. E também, quando aplicado o teste estatístico das duas médias este método não se demonstrou equivalente a nenhuma das outras duas técnicas aplicadas. Conclui-se que esta método não foi adequada para determinação de volume assoreado de reservatório neste estudo de caso.

O método de redução das sondagens batimétricas ao nível d' água instantâneo, rastreado com o RTK instalado na margem do reservatório, no início e no final de cada dia de levantamento apresentou de acordo com o teste de hipóteses das duas médias, resultado equivalente as observações do nível d' água feitas pela régua linimétrica. Estes dois métodos também atendem ao PEC "B" e o erro total propagado é inferior as IVT para a ordem 1a, para levantamentos 
hidrográficos. Portanto estes dois métodos podem ser aplicados no monitoramento de assoreamento de reservatórios.

\section{AGRADECIMENTOS}

A ANEEL e a COPEL pelo apoio financeiro no projeto intitulado "Levantamento geológicoestrutural da região e entorno da barragem da UHE Mauá, uma abordagem inovadora para o monitoramento geodésico nos pontos de risco".

\section{REFERÊNCIAS BIBLIOGRÁFICAS}

Agência Nacional de Águas (ANA). Orientações para atualização das curvas cota $x$ área $x$ volume. Superintendência de Gestão da Rede Hidrometeorológica, Brasília, 2013.

Brasil. Decreto-lei n.89.817, de 20 de junho de 1984. Diário Oficial da República Federativa do Brasil, Brasília, 22 julho, 1984.

Bronsvoort, Koen. "Sedimentation in reservoirs: Investigating reservoir preservation options and the possibility of implementing water Injection dredging in reservoirs". Dissertação de mestrado, Delft University of Technology, Holanda, 2013.

Carvalho, Newton O. et al. "Estudos do assoreamento de grandes reservatórios: o caso de Tucuruî". Trabalho apresentado no. 25. Seminário Nacional de Grandes Barragens, Salvador, 2003.

Carvalho, Newton O., Filizola Junior, Naziano P., Dos Santos, Paulo M. C., Lima, Jorge E. F. W. Guia de avaliação de assoreamento de reservatórios. Brasília: ANEEL, 2000.

Carvalho, Newton O. Hidrossedimentologia prática. 2. ed. Rio de Janeiro: Interciência, 2008.

Da Silva, Sebastião A. "Avaliação do assoreamento do lago Bonsucesso, Jataí - GO". Dissertação de Mestrado, Universidade Federal do Paraná, Curitiba, 2007.

Ferreira, Ítalo. O. "Coleta, processamento e análise de dados batimétricos visando a representação computacional do relevo submerso utilizando interpoladores determinísticos e probabilísticos”. Dissertação de Mestrado, Universidade Federal de Viçosa, Viçosa, 2013.

Kuwajima, Julio. I. "Análise do modelo SWAT como ferramenta de prevenção e de estimativa de assoreamento no reservatório do Lobo (Itirapina/Brotas/ SP)". Dissertação de Mestrado, Universidade de São Paulo, São Paulo, 2012.

Marques, Jair Mendes; Marques, Marcos Augusto Mendes. Estatística Básica para os cursos de engenharia. Curitiba: Domínio do Saber, 2005. 272 p.

Mônico, João F. G. Posicionamento pelo GNSS: descrição, fundamentos e aplicações. 2 ed. São Paulo: Editora UNESP, 2008.

Organização Hidrográfica Internacional (OHI). Manual de Hidrografia. Publicação C13. Tradução. Lisboa: Instituto Hidrográfico - Portugal, 2005. 
Organização Hidrográfica Internacional (OHI). Especificações da OHI para Levantamentos Hidrográficos. Publicação Especial $n^{\circ}$ 44. Traduzido por Peter Esteves. 5. ed. Niterói: Diretoria de Hidrografia e Navegação - Brasil, 2008.

Ramos, Alexandre. M. "Aplicação, investigação e análise da metodologia de reduções batimétricas através do método GPS diferencial preciso". Dissertação de mestrado, Universidade Federal do Paraná, Curitiba, 2007.

Ribeiro, Selma R. A., Centeno, Jorge A. S., Krueger, Cláudia P. "Estimativa de profundidade a partir de levantamento batimétrico e dados IKONOS II mediante redes neurais artificiais". Boletim de Ciências Geodésicas, v. 14, n. 2, p. 171-185,Curitiba, 2008.

Seeber, Günter. Satellite Geodesy: foundations, methods and applications. 2nd completely revised and extended edition. Berlin: Walter de Gruyter, 2003.

Tedesco, Andrea. "Estimativa de profundidades utilizando imagens de alta resolução apoiadas por dados de levantamento batimétrico". Dissertação de Mestrado, Universidade Federal do Paraná, Curitiba, 2003.

Teledyne Reson: NaviSound 215 Portable Hydrographic Echosounder. Acesso em 12 de dezembro de 2014. http://www.teledyne-reson.com/wp-content/uploads/2011/06/NaviSound215.pdf .

Topcon Positioning Systems. Hiper ${ }^{\circledR}$ Lite and Hiper ${ }^{\circledR}$ Lite + Operator's Manual. Estados Unidos da América, 2004. Manual.

Twenhofel, William H. Principles of Sedimentation. New York: McGraw Hill Book Company, 1939.

UHE Mauá: ficha técnica. Acesso em 06 de março de 2014. http://www.usinamaua.com.br/ausina/ficha-tecnica

US Army Corps of Engineers (USACE), EM 1110-2-1003 Engineering and Design Hydrographic Surveying. Change 1. Department of the Army, Washington, 2004.

Recebido em outubro de 2015.

Aceito em abril de 2016. 